\title{
Holmium Laser Enucleation of Prostate for Benign Prostatic Hyperplasia: Seoul National University Hospital Experience
}

\author{
Jungbum Bae, Minsoo Choo, Ji Hyun Park, Jin Kyu Oh, Jae-Seung Paick, Seung-June Oh \\ Department of Urology, Seoul National University Hospital, Seoul National University College of Medicine, Seoul, Korea
}

Purpose: The objective of this study was to report the experience acquired at the Seoul National University Hospital with Holmium Laser Enucleation of Prostate (HoLEP), combined with mechanical morcellation for symptomatic benign prostatic hyperplasia $(\mathrm{BPH})$.

Methods: A retrospective review was performed on the clinical data of 309 consecutive patients who underwent HoLEP at our institution between July 2008 and June 2010. All patients were evaluated preoperatively for prostate volume by transrectal ultrasound, maximum urinary flow rate (Qmax), International Prostate Symptoms Score (IPSS) and quality of life (QoL) score. Periand postoperative parameters were evaluated and patients were followed-up at 1-, 3-, 6-, and 12- months with the aforementioned investigations.

Results: The patients' mean age was $68.3( \pm 6.5)$ years and mean prostate volume was $55.6( \pm 23.6) \mathrm{mL}$. Mean enucleation time was $56.2( \pm 25.1)$ minutes, mean morcellation time was $11.3( \pm 9.5)$ minutes, and the mean resected weight of the prostate was $20.8( \pm 16.9) \mathrm{g}$. The mean catheter indwelling period was $1.9( \pm 1.7)$ days and mean hospital stay was $2.9( \pm 1.5)$ days. Significant improvement was noted in Qmax, IPSS, and QoL at the 1-year follow-up compared with baseline $(\mathrm{P}<0.01)$. At 1 month $17.2 \%$ of patients complained of irritative urinary symptoms, which were typically self-limiting within 3 months. Transient stress incontinence was reported in $15.2 \%$ of patients. No patient experienced persistent obstructive symptoms that required reoperation.

Conclusions: Our study showed that HoLEP is a safe and effective therapeutic modality for BPH.

Keywords: Benign prostatic hyperplasia; Holmium; Lasers; Prostatectomy

\section{INTRODUCTION}

Lower urinary tract symptoms (LUTS) due to benign prostatic hyperplasia (BPH) are major cause of discomfort among elderly men [1]. Transurethral resection of prostate (TURP) has been accepted as the gold standard for the surgical management of symptomatic BPH [2]. Recently, however, relatively less invasive treatment modalities have been introduced, resulting in lower morbidity and excellent voiding symptom improvement [3].

In 1995, the first description of laser prostatectomy using a Holmium laser was published by Gilling [4]. Ever since the introduction of Holmium laser enucleation of prostate (HoLEP), it has become accepted as a treatment modality with excellent outcomes. Compared with conventional treatment modalities, such as TURP and open prostatectomy, HoLEP shows similar postoperative outcomes associated with lower morbidities [5,6]. In 2008, the HoLEP procedure became popularized in the Republic of Korea for the treatment of BPH. Despite a steep learning curve, this technique has been acquired by many Korean urologists. Although results over a 3-year follow-up period have been reported by foreign groups, mid-term postoperative follow-up results have not been reported in Korea [5]. Two years after the introduction of HoLEP, we herein present our intermediate-term follow-up results.
Corresponding author: Seung-June $\mathrm{Oh}$

Department of Urology, Seoul National University Hospital, Seoul National University College of Medicine, 101 Daehak-ro, Jongno-gu,

Seoul 110-744, Korea

Tel: +82-2-2072-2406 / Fax: +82-2-742-4665 / E-mail: sjo@snu.ac.kr

Submitted: November 30, 2010 / Accepted after revision: March 20, 2011
This is an Open Access article distributed under the terms of the Creative Commons Attribution Non-Commercial License (http://creativecommons.org/licenses/by-nc/3.0/) which permits unrestricted non-commercial use, distribution, and reproduction in any medium, provided the original work is properly cited. 


\section{MATERIALS AND METHODS}

A retrospective study was conducted in 309 patients complaining of LUTS who underwent HoLEP combined with morcellation at our institute by two surgeons (SJO, JSP) between July 2008 and June 2010. All patients presented with LUTS due to BPH with or without bladder overactivity. Patient demographics, including medical history and pre- and postoperative status were reviewed. Preoperative parameters such as; physical examination including digital rectal examination, urinalysis and urine culture, serum prostate-specific antigen (PSA), International Prostate Symptom Score (IPSS) questionnaire with quality of life (QoL) and uroflowmetry (UFM) with post void residual (PVR) measurement by ultrasound were investigated. Prostate volume and transitional zone volume were measured by using transrectal ultrasound (TRUS). When prostate cancer was clinically suspected, preoperative prostate biopsy was performed. Postoperatively, IPSS, UFM and PVR were investigated during follow-up at 1, 3, 6, and 12 months. Serum PSA and TRUS measurements were performed at 6 months. The postoperative biopsy result was recorded if malignant neoplasm was present. Some patients underwent cystoscopic examination for urinary tract complications.

Operative procedures were similar to those described previously [7]. Briefly a 26Fr resectoscope (Karl Storz GmbH \& Co., Tuttlingen, Germany) was used for enucleation of the prostate. A $550 \mu \mathrm{m}$ end-firing laser fiber (SlimLine, Lumenis Ltd, Yokneam, Israel) was engaged with an $80 \mathrm{~W}$ holmium neodymium: yttrium-aluminum-garnet laser (VersaPulse PowerSuite, Lumenis Ltd). Energy power was usually set at $2 \mathrm{~J}$ and 50 $\mathrm{Hz}$, and for hemostasis at $2 \mathrm{~J}$ and $40 \mathrm{~Hz}$. Continuous irrigation was applied with normal saline during enucleation and morcellation. Tissue morcellation was performed with a VersaCut morcellator (Lumenis Ltd) through a 0 degree rectangular nephroscope (Karl Storz GmbH \& Co.). During the transurethral procedure the outer sheath was always in the urethra, because the resectoscope and nephroscope were exchangeable in the outer sheath. At completion of the morcellation, a 22Fr 3-way urethral catheter was inserted for continuous bladder irrigation with normal saline. Most patients were discharged after Foley catheter removal the following day.

Operative documents captured enucleation time, morcellation time, retrieved tissue weight, pathologic findings, catheter time, hospital stay and operation-related complications. Complications included perioperative events (capsular perforation, mucosal injury, transfusion, clot retention, recatherterization), postoperative sustaining voiding symptoms (incontinence, irritative symptoms, urinary tract infection [UTI]) and postoperative morbid finding (urethral stricture, bladder neck contracture). Data were statistically analyzed by using the Student's t-test or analysis of variance, and are presented as ranges and means \pm standard deviation of the mean.

This study was approved by the Institutional Review Board of Seoul National University Hospital.

\section{RESULTS}

The baseline characteristics of the patients are summarized in Table 1. Mean patients age was 68.3 years. Most patients had previously received an alpha blocker. One third of the patients $(116,34.5 \%)$ had a prostate larger than $60 \mathrm{~mL}$. Mean maximum urinary flow rate $(\mathrm{Q} \max )$ and $\mathrm{PVR}$ were $10.3 \mathrm{~mL} / \mathrm{sec}$ and $72.2 \mathrm{~mL}$, respectively. Mean follow-up duration was 12

Table 1. Patient demographics

\begin{tabular}{lc}
\hline Parameters & Value \\
\hline No. of patients & 309 \\
Age (yr) & $68.3(51-88)$ \\
Symptom duration (mo) & $27.1(1-360)$ \\
BMI $\left(\mathrm{kg} / \mathrm{m}^{2}\right)$ & $24.1(13.8-31.8)$ \\
Preoperative medical history & \\
Diabetes melitus & $51(16.5)$ \\
Neurologic disease & $35(7.4)$ \\
Cardiovascular disease & $25(7.4)$ \\
Preoperative medications & \\
Alpha-blocker & $214(69.3)$ \\
5a-reductase inhibitor & $81(26.2)$ \\
Anticholinergics & $27(8.7)$ \\
Evaluation data & \\
Serum PSA (ng/mL) & $3.5(0.3-36.7)$ \\
Prostate volume (mL) & $55.6(11.9-162)$ \\
Transitional zone volume (mL) & $29.5(4-107)$ \\
Qmax (mL/sec) & $10.3(0.8-25)$ \\
IPSS & $19.1(3-35)$ \\
QoL & $4.1(1-6)$ \\
\hline
\end{tabular}

Values are presented as mean (range) or number (\%).

BMI, body mass index; PSA, prostate-specific antigen; Qmax, maximum urinary flow rate; IPSS, international prostate symptom score; QoL, quality of life score. 
Table 2. Perioperative findings and operative efficiency

\begin{tabular}{lc}
\hline Parameters & Mean (range) \\
\hline Enucleation time (min) & $56.2(10-180)$ \\
Morcellation time (min) & $11.3(1-90)$ \\
Used energy (KJ) & $101.6(11.3-233.6)$ \\
Resected weight (g) & $20.8(0.2-84.3)$ \\
Enucleation efficiency (g/min) & $0.37(0.01-1.47)$ \\
Morcellation efficiency (g/min) & $2.06(0.1-7.7)$ \\
Catheter duration (day) & $1.9(0-16)$ \\
Hospital stay (day) & $2.9(1-18)$
\end{tabular}

months (range, 6 to 28 months).

Perioperative data are presented in Table 2. Seventeen (5\%) patients who had bladder stones underwent lithotripsy by holmium laser before enucleation of an adenoma. The mean enucleation and morcellation efficiency were $0.37 \mathrm{~g} / \mathrm{min}$ and 2.06 $\mathrm{g} / \mathrm{min}$, respectively. The difference in operative efficiency according to prostate size was statistically available for the parameters of enucleation efficiency and morcellation efficiency (data not shown). Only one patient underwent pure laser-assisted incision of the bladder neck.

Table 3 shows parameters related to complications. Intraoperative complications included bladder injury (9.1\%), capsular perforation (5.8\%), additional transurethral resection (TUR) (16.5\%), incomplete morcellation (6.5\%) and sustained bleeding during enucleation (25.6\%). Mean catheter duration and hospital stay were 1.9 days and 2.9 days, respectively. Thus, most patients were discharged without a Foley catheter within 3 days of admission. Five patients required subsequent coagulation for bleeding control under anesthesia and two patients required only cystoscopic clot evacuation with local anesthesia. In this series, six patients required postoperative transfusion due to postoperative hemoglobin decrease. Thirty-one patients (9.1\%) were recatheterized on the day of Foley removal or several days later due to urinary retention. After recatheterization, removal of the Foley catheter was determined by clinical decision, taking into account patient age, general condition, comorbidity and operative findings. Extremely long catheter duration was related with patient's comorbidities.

During the follow-up, major complaints consisted of persistent irritative symptoms (17.2\%), UTI including epididymitis (2.6\%), urinary incontinence (15.2\%), and urethral stricture confirmed by urethroscopy (3.2\%). These complications tended to improve within a few months.
Table 3. Perioperative complications

\begin{tabular}{|c|c|}
\hline Types of complication & No. $(\%)$ \\
\hline \multicolumn{2}{|l|}{ Intraoperative } \\
\hline Adjuvant TURP & $51(16.5)$ \\
\hline Incomplete morcellation & $20(6.5)$ \\
\hline Bladder injury & $28(9.1)$ \\
\hline Capsular perforation & $18(5.8)$ \\
\hline Bleeding & $79(25.6)$ \\
\hline False way of urethra & $4(1.3)$ \\
\hline \multicolumn{2}{|l|}{ Immediate postoperative } \\
\hline Cystoscopic clot evacuation & $2(0.6)$ \\
\hline Recatheterization & $31(10.0)$ \\
\hline Reoperation for bleeding control & $5(1.6)$ \\
\hline Transfusion & $6(1.9)$ \\
\hline Urinary incontinence & $38(12.3)$ \\
\hline Urgency & $18(5.8)$ \\
\hline \multicolumn{2}{|l|}{ Postoperative 1 month $(\mathrm{n}=309)$} \\
\hline Urinary incontinence & $47(15.2)$ \\
\hline Urgency & $53(17.2)$ \\
\hline UTI & $8(2.6)$ \\
\hline Dysuria & $8(2.6)$ \\
\hline Urethral stricture & $5(1.6)$ \\
\hline \multicolumn{2}{|l|}{ Postoperative 3 months $(\mathrm{n}=307)$} \\
\hline Urinary incontinence & $28(9.1)$ \\
\hline Urgency & $31(10.1)$ \\
\hline UTI & $2(0.7)$ \\
\hline Dysuria & $3(1.0)$ \\
\hline Urethral stricture & $5(2.33)$ \\
\hline \multicolumn{2}{|l|}{ Postoperative 6 months $(n=168)$} \\
\hline Urinary incontinence & $12(7.1)$ \\
\hline Urgency & $12(7.1)$ \\
\hline UTI & $1(0.6)$ \\
\hline Dysuria & $1(0.6)$ \\
\hline Urethral stricture & $3(1.8)$ \\
\hline \multicolumn{2}{|l|}{ Postoperatively 12 months $(n=106)$} \\
\hline Urinary incontinence & $5(4.7)$ \\
\hline Urgency & $6(5.7)$ \\
\hline UTI & $1(0.9)$ \\
\hline Dysuria & $2(1.9)$ \\
\hline Urethral stricture & $1(0.9)$ \\
\hline \multicolumn{2}{|l|}{ Postoperative medication } \\
\hline Anticholinergics & $63(20.4)$ \\
\hline Alpha-blocker & $6(1.9)$ \\
\hline Desmopressin & $3(1.0)$ \\
\hline Malignancies postoperative pathology reported & $17(5.5)$ \\
\hline
\end{tabular}

TURP, transurethral resection of prostate; UTI, urinary tract infection. 
Table 4. Voiding parameters as efficacy profile

\begin{tabular}{|c|c|c|c|c|c|c|}
\hline & $\begin{array}{l}\text { Preoperative } \\
(\mathrm{n}=309)\end{array}$ & $\begin{array}{l}\text { Preoperative }{ }^{\mathrm{b})} \\
\quad(\mathrm{n}=106)\end{array}$ & $\begin{array}{c}1 \text { mo } \\
(n=302)\end{array}$ & $\begin{array}{c}3 \mathrm{mo} \\
(\mathrm{n}=217)\end{array}$ & $\begin{array}{c}6 \text { mo } \\
(n=167)\end{array}$ & $\begin{array}{c}12 \mathrm{mo} \\
(\mathrm{n}=106)\end{array}$ \\
\hline $\mathrm{Qmax}(\mathrm{mL} / \mathrm{sec})$ & $10.3 \pm 4.6$ & $10.6 \pm 4.1$ & $18.7^{\mathrm{a})} \pm 9.8$ & $19.8^{\mathrm{a})} \pm 11.1$ & $19.5^{\mathrm{a})} \pm 8.5$ & $19.5^{\mathrm{a})} \pm 9.5$ \\
\hline PVR (mL) & $72.2 \pm 100$ & $93.1 \pm 118.1$ & $22.9^{\mathrm{a})} \pm 32.8$ & $22.9^{\mathrm{a})} \pm 42.4$ & $21.1^{\mathrm{a})} \pm 39.7$ & $18.9^{\mathrm{a})} \pm 38.4$ \\
\hline IPSS & $19.1 \pm 7.5$ & $19.3 \pm 7.2$ & $10.7^{\mathrm{a})} \pm 7.9$ & $8.1^{\text {a) }} \pm 6.6$ & $7.9^{\mathrm{a})} \pm 6.4$ & $7.7^{\text {a) }} \pm 6.0$ \\
\hline Voiding symptom & $11.5 \pm 5.2$ & $11.7 \pm 4.7$ & $4.7^{\mathrm{a})} \pm 4.8$ & $3.3^{\text {a) }} \pm 4.5$ & $3.7^{\text {a) }} \pm 4.5$ & $3.8^{\mathrm{a})} \pm 4.4$ \\
\hline Storage symptom & $7.7 \pm 3.5$ & $7.9 \pm 3.6$ & $6.2 \pm 4.1$ & $4.8^{\text {a) }} \pm 3.1$ & $4.2^{\mathrm{a})} \pm 2.9$ & $3.9^{\text {a) }} \pm 2.7$ \\
\hline QoL & $4.1 \pm 1.1$ & $4.2 \pm 1.2$ & $2.8^{\mathrm{a})} \pm 1.7$ & $2.1^{\mathrm{a})} \pm 1.5$ & $1.7^{\mathrm{a})} \pm 1.5$ & $1.8^{\mathrm{a})} \pm 1.4$ \\
\hline Serum PSA $(\mathrm{ng} / \mathrm{mL})$ & $3.5 \pm 4.1$ & $3.5 \pm 4.7$ & & $1.0^{\text {a) }} \pm 0.8$ & $1.0^{\text {a) }} \pm 0.7$ & $1.1^{\text {a) }} \pm 0.7$ \\
\hline Prostate vol (mL) & $55.6 \pm 23.6$ & $52.7 \pm 21.3$ & & & $24.1^{\mathrm{a})} \pm 7.4$ & \\
\hline
\end{tabular}

Qmax, maximum urinary flow rate; PVR, post void residual; IPSS, international prostate symptom score; QoL, quality of life score; PSA, prostatespecific antigen.

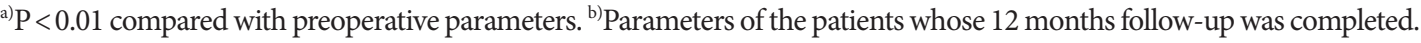

Voiding parameters became favorable as follow-up continued (Table 4). Qmax and PVR were dramatically improved immediately after the operation. At the 1-year follow-up, Qmax, IPSS, and QoL showed significant improvement compared with baseline $(\mathrm{P}<0.01)$. Within the prostate symptom score, however, the storage symptom score showed gradual improvement. Serum PSA decreased with statistical significance $(\mathrm{P}<0.01)$. Postoperative urinary incontinence appeared in 47 (15.2\%) patients (urge 38, stress 29). Urinary incontinence appeared within 1 month in most patients and persisted for about 2 months. Stress urinary incontinence was associated with prostate size (divided with cut off value $50 \mathrm{~mL}, \mathrm{P}=0.046$ ), intraoperative capsular perforation $(\mathrm{P}=0.045)$ and bladder mucosal injury $(\mathrm{P}=0.009)$, but was not correlated with preoperative presence of detrusor overactivity $(\mathrm{P}=0.204)$ and preoperative incontinence $(\mathrm{P}=0.623)$.

Indolent malignancies were detected in 17 patients, of whom 1 patient experienced invasive transitional cell carcinoma (TCC) and the remainder presented with prostate adenocarcinoma. At the time of finalizing this article for publication, there had been no reoperations for recurrence of $\mathrm{BPH}$.

\section{DISCUSSION}

As reported in the literature, HoLEP is assumed to provide eminent physical properties terms of BPH surgery and morbidity [3]. HoLEP has proven to be a good alternative to TURP and open prostatectomy with excellent hemostasis $[5,6]$. In 2008, HoLEP was introduced in Korea owing to its efficiency and safety. However, several challenges exist. A steep learning curve is the main hurdle to overcome for urologists, particularly in the initial phase of experience. According to several articles, the steep learning curve can be surmounted by performing consecutive HoLEP procedures [8-10]. After the initial experience, postoperative results should be analyzed once a consistent technique is applied. As such, we began to analyze intermediateterm results 2 years after the introduction of HoLEP in Korea.

Of the operative parameters, operative time and efficiency (including enucleation and morcellation) were comparable with previously reported outcomes $[11,12]$. In our previous series, after overcoming the learning curve, the efficiency of HoLEP became stable and the general operative parameters were consistent [10]. Voiding parameters, such as Qmax and IPSS, which are indicative of voiding symptom relief, dropped immediately after the operation and this trend continued in the follow-up period. Regarding the storage symptom score sum, the range of reduction was not as wide as for the voiding symptom scores sum and Qmax in the first months. It was associated with relatively high rates of irritative symptoms and incontinence during the initial follow-up period. A previous report on the mid-term outcomes of HoLEP confirmed its sustainability [5]. In the present report, there was no need for additional adenoma resection during the follow-up period. This observation showed the long-term durability of the operative outcomes.

Regarding perioperative events, incomplete enucleation, additional TUR and incomplete morcellation appeared in the initial and late series [10]. In cases of incomplete enucleation, we applied additional TUR to complete the prostate resection and to make the prostatic urethra surface smooth. If mechanical morcellation was imperfect, the remnant tissue was extracted 
by use fo cystoscopic foreign body forceps. The reason for this observation after surmounting the learning curve can be assumed to be fibrotic tissue that was too firm to be easily engaged by the laser fiber and morcellator blades [11]. Bladder injury and capsular perforation could still be seen late in the series. This can be explained by the tendency of surgeons to perform rapid and complete operations; therefore, the risks of perforation did not decrease [10]. However, most complications had a tendency to decrease as experience was accumulated. In our series, there was only one case of full-thickness ureteral orifice injury, whereas most cases were due to shallow mucosal injury. Most cases of bladder injury were managed just like routine cases or in some were caused by prolonged indwelling of the urinary catheter. Capsular perforations were addressed by coagulation by TUR. The transfusion rate was $1.6 \%$. Most cases were in the early series and the transfusion rate was comparable to that described in other reports [13].

Irritative symptoms were the major complaints in the initial follow-up period. These symptoms were assumed to originate from capsular irritation by laser energy [14]. However, these were generally self-limiting within 3 months. Vavassori et al. [11] reported that the $28 \%$ of patients who complained of irritative voiding symptom at the first follow-up month soon decreased to $10 \%$ within 3 months. These patients probably had inflammatory circumstances that may be related to tissue reactivation in the prostate surgical plane [15]. In most patients the symptom grade was generally mild.

In this series, the incidence of early urinary incontinence, including urgency and stress, was relatively high (15.2\%), but lower than in other series [14]. The incidence was reduced to $9.1 \%$ at 3 months and to $7.1 \%$ at 6 months. Most patients improved during the initial 6 months postoperatively, and the mean symptom duration was 2 months. Early urinary incontinence might have originated from transient urethral dilatation of the prostate apex structure, resulting in temporal external sphincter damage [9]. To avoid this complication, Fong et al. [16] advocated prudence so as not to incise the sphincter base in the anterior area of the prostate. We analyzed the relationship between urinary incontinence and preoperative parameters. Comorbidities including diabetes mellitus, neurologic disease, and detusor overactivity on urodynamic study were not statistically related to incontinence.

Several studies indicated a lower incidence of urethral stricture following HoLEP than after TURP and open prostatectomy $[17,18]$. In our series, the risk of urethral stricture was simi- lar to TURP and open prostatectomy. Most strictures were found on the meatus or the bulbous urethra, which were generally dilated in the outpatient clinic. Only one patient experienced recurrent urethral strictures and underwent repeated endoscopic urethrotomy. Urethral strictures, in this series, did not show any correlation with preoperative stricture or prostate size, whereas other researchers reported an association with the learning curve [13]. We found bladder neck contracture in two patients, first detected between 3 and 6 months of follow-up. This relatively low rate of stricture was due to gentle handling of the scope, preoperative calibration in some cases and lubrication during the procedure [6].

The prostate size measured at 6 months revealed a mean decrease of $27.8 \mathrm{~mL}$, comparable to the mean enucleation weight (20.8 g) gauged immediately after the operation. Although not all patients underwent measurement of prostate size at 6 months, these data confirmed anatomical reduction of the enlarged prostate. The PSA level measured 6 months postoperatively represented a considerable reduction, which indirectly indicated urinary symptom improvement.

Pathologic examination was performed in all cases and revealed malignancy in 17 patients (5\%), including 1 patient with invasive TCC. The remaining patients were diagnosed with prostate adenocarcinoma, which was managed appropriately. This finding is comparable with reports of TURP and open prostatectomy $[19,20]$. The possibility of histological examination is a merit of HoLEP compared with ablative modalities such as holmium ablation of prostate or photoselective vaporization. In addition, the natural history of incidentally detected prostate cancer will be addressed in another study.

There are limitations to our study. First, this study was a retrospective cross-sectional review of data, which limits accurate comparison between different subsets of patients. Second, the patient data were limited to a relatively short follow-up period. Several authors reported 3 years follow-up results with sizable population [5]. Furthermore, a significant number of patients were lost to follow-up. This may be due to the fact that once patients experienced symptom improvement; they became unwilling to visit the clinic because their conditions were not considered life threatening.

In conclusion, our intermediate postoperative follow-up data show that HoLEP is an effective and relatively safe surgical procedure for BPH. Further follow-up is needed to prove the longterm durability of HoLEP. 


\section{CONFLICT OF INTEREST}

No potential conflict of interest relevant to this article was reported.

\section{REFERENCES}

1. Arrighi HM, Metter EJ, Guess HA, Fozzard JL. Natural history of benign prostatic hyperplasia and risk of prostatectomy. The Baltimore Longitudinal Study of Aging. Urology 1991;38(1 Suppl):4-8.

2. AUA Practice Guidelines Committee. AUA guideline on management of benign prostatic hyperplasia (2003). Chapter 1: Diagnosis and treatment recommendations. J Urol 2003;170(2 Pt 1):530-47.

3. Kuntz RM. Current role of lasers in the treatment of benign prostatic hyperplasia (BPH). Eur Urol 2006;49:961-9.

4. Gilling PJ, Cass CB, Malcolm AR, Fraundorfer MR. Combination holmium and Nd: YAG laser ablation of the prostate: initial clinical experience. J Endourol 1995;9:151-3.

5. Ahyai SA, Lehrich K, Kuntz RM. Holmium laser enucleation versus transurethral resection of the prostate: 3-year follow-up results of a randomized clinical trial. Eur Urol 2007;52:1456-63.

6. Kuntz RM, Lehrich K. Transurethral holmium laser enucleation versus transvesical open enucleation for prostate adenoma greater than $100 \mathrm{gm}$ : a randomized prospective trial of 120 patients. J Urol 2002;168(4 Pt 1):1465-9.

7. Gilling PJ, Kennett K, Das AK, Thompson D, Fraundorfer MR. Holmium laser enucleation of the prostate (HoLEP) combined with transurethral tissue morcellation: an update on the early clinical experience. J Endourol 1998;12:457-9.

8. Shah HN, Mahajan AP, Sodha HS, Hegde S, Mohile PD, Bansal MB. Prospective evaluation of the learning curve for holmium laser enucleation of the prostate. J Urol 2007;177:1468-74.

9. Seki N, Mochida O, Kinukawa N, Sagiyama K, Naito S. Holmium laser enucleation for prostatic adenoma: analysis of learning curve over the course of 70 consecutive cases. J Urol 2003;170:1847-50.

10. Bae J, Oh SJ, Paick JS. The learning curve for holmium laser enucleation of the prostate: a single-center experience. Korean J Urol 2010; 51:688-93.

11. Vavassori I, Valenti S, Naspro R, Vismara A, Dell'Acqua V, Manzetti
A, et al. Three-year outcome following holmium laser enucleation of the prostate combined with mechanical morcellation in 330 consecutive patients. Eur Urol 2008;53:599-604.

12. Elzayat EA, Habib EI, Elhilali MM. Holmium laser enucleation of the prostate: a size-independent new "gold standard". Urology 2005; 66(5 Suppl):108-13.

13. Shah HN, Mahajan AP, Hegde SS, Bansal MB. Peri-operative complications of holmium laser enucleation of the prostate: experience in the first 280 patients, and a review of literature. BJU Int 2007; 100:94-101.

14. Naspro R, Suardi N, Salonia A, Scattoni V, Guazzoni G, Colombo R, et al. Holmium laser enucleation of the prostate versus open prostatectomy for prostates $>70 \mathrm{~g}$ : 24-month follow-up. Eur Urol 2006;50:563-8.

15. Larner TR, Agarwal D, Costello AJ. Day-case holmium laser enucleation of the prostate for gland volumes of $<60 \mathrm{~mL}$ : early experience. BJU Int 2003;91:61-4.

16. Fong BC, Elhilali MM. Holmium: YAG Laser enucleation of the prostate: multimedia description from a trainee's perspective. J Endourol 2004;18:791-4.

17. Montorsi F, Naspro R, Salonia A, Suardi N, Briganti A, Zanoni M, et al. Holmium laser enucleation versus transurethral resection of the prostate: results from a 2-center, prospective, randomized trial in patients with obstructive benign prostatic hyperplasia. J Urol 2004;172(5 Pt 1):1926-9.

18. Wilson LC, Gilling PJ, Williams A, Kennett KM, Frampton CM, Westenberg AM, et al. A randomised trial comparing holmium laser enucleation versus transurethral resection in the treatment of prostates larger than 40 grams: results at 2 years. Eur Urol 2006;50: 569-73.

19. Naspro R, Freschi M, Salonia A, Guazzoni G, Girolamo V, Colombo R, et al. Holmium laser enucleation versus transurethral resection of the prostate. Are histological findings comparable? J Urol 2004;171:1203-6.

20. Gratzke C, Schlenker B, Seitz M, Karl A, Hermanek P, Lack N, et al. Complications and early postoperative outcome after open prostatectomy in patients with benign prostatic enlargement: results of a prospective multicenter study. J Urol 2007;177:1419-22. 